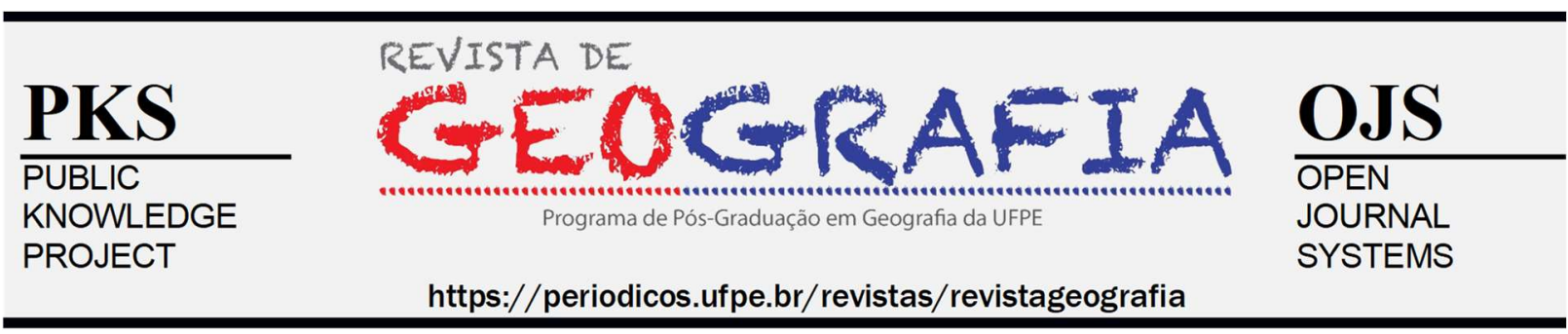

\title{
BALANÇO HÍDRICO SEQUENCIAL EM SÃO BENTO DO UNA - PE, BRASIL, VISANDO APOIO A AVICULTURA
}

\author{
Raimundo Mainar de Medeiros ${ }^{1}$ \\ ${ }^{1}$ Universidade Federal Rural de Pernambuco.E-mail: mainarmedeiros@gmail.com \\ Artigo recebido em 22/01/2020 e aceito em 31/05/2020

\begin{abstract}
RESUMO
O balanço hídrico sequencial mostrar-se como uma das ferramentas de fundamental importância, permitindo averiguar o evento da disponibilidade hídrica no solo em termos de deficiência e excedentes em períodos específicos. Objetiva-se realizar a estimativa do computo do balanço hídrico sequencial para o município de São Bento do Una com o intuito de verificar a contribuição do armazenamento, represamento de água, em relação à crise hídrica, além de gerar e disponibilizar subsídios para elaboração de planejamento e projeto da área estudada. Os dados pluviais médios mensais do período de 1920 a 2018 foram adquiridos da Superintendência do Desenvolvimento do Nordeste e da Agencia de Água e Clima do Pernambuco. A temperatura média do ar foi estimada pelo software estima- $\mathrm{T}$, levando em consideração as coordenadas geográficas. Os impactos climáticos têm provocado modificações no balanço hídrico da região na última década. A degradação ambiental, o efeito local da ação do homem tem por si só acelerado o processo de modificação do clima regional, com isso afetando diretamente as condições do regime de precipitações e da disponibilidade de água no solo. Sendo de extrema necessidade o uso de captação de água de chuva e de outras fontes de armazenamento para a sobrevivência humana, animal e vegetal, contribuindo deste modo ao setor agropecuário e avícola da região. Os impactos climáticos podem vim a provocar modificações no balanço hídrico da região visto que se esperam chuvas fortes e de curta duração acarretando queda na produção avícola.
\end{abstract}

Palavras-chave: Flutuações pluviais e térmicas; clima; fatores culturais.

\section{SEQUENTIAL WATER BALANCES IN SÃO BENTO OF UNA - PE, BRAZIL, AIMING TO SUPPORT BEEKEEPING}

\begin{abstract}
Sequential water balance has proved to be one of the most important tools, allowing to investigate the event of water availability in the soil in terms of deficiency and surpluses in specific periods. The objective is to estimate the sequential water balance computation for the city of São Bento do Una in order to verify the contribution of storage, damming, in relation to the water crisis, and to generate and make available subsidies for planning. and project of the studied area. The monthly average rainfall data from 1920 to 2018 were obtained from the superintendence of the northeast development and from the Pernambuco water and climate agency. The average air temperature was estimated by the T-estimation software, taking into account the geographical coordinates. Climate impacts have caused changes in the region's water balance over the past decade. Environmental degradation, the local effect of human action, has by itself accelerated the process of regional climate modification, thereby directly affecting the conditions of the rainfall regime and the availability of water in the soil. The use of rainwater harvesting and other storage sources for human, animal and plant survival is extremely necessary, thus contributing to the region's agricultural and poultry sector. Climate impacts may have led to changes in the region's water balance as heavy and short-term rainfall is expected leading to a drop in poultry production.
\end{abstract}

Keywords: Rain and thermal fluctuations; climate; cultural factors. 


\section{INTRODUÇÃO}

A proeminência da estimativa do balanço hídrico sequencial (BHS) pauta-se na importância que a água tem no seu armazenamento, represamento, sobrevivência humana, vegetal e animal aos desenvolvimentos dos grãos, agropecuário, citricultura, fruticultura, avicultura, hortifrutigranjeiro, irrigação, reduções nos consumos de energia e água além de redução de tempo de bombeamento d'água e laser. O BHS simula a contribuição de variação na quantidade d'água em uma amostra definida de solo sobre determinado período de tempo, indicando a capacidade de retenção de água por período em função de alguns parâmetros, tais como: tipo de solo, temperatura, índices pluviais mensais e anuais. Para efeitos de balanço é necessário definir grandezas como positivas e negativas, e o volume de entrada e saída d'água no solo. O balanço hídrico como unidade de gerenciamento, permite classificar o clima de uma região, realizar o zoneamento agroclimático e ambiental, o período de disponibilidade e necessidade hídrica no solo, além de favorecer ao gerenciamento integrado dos recursos hídricos (LIMA, 2009).

Estudo de Medeiros et al. (2012) para o município de Picuí - PB indicaram que os índices pluviais não serão suficientes para vários tipos de culturas, o que inviabiliza o cultivo de sequeiro, caso os cenários pessimistas sejam sancionados. $\mathrm{O}$ autor ainda adverte que diante de um cenário pessimista, à condição para o armazenamento d'água pluvial para o consumo humano e animal sofrerá impactos significativos, sendo necessário, portanto, um planejamento para convivência com a seca que possibilitem o armazenamento d'água e a minimização dos impactos da falta de chuvas. Ainda de acordo com Medeiros et al. (2013) a técnica do balanço hídrico fornece o saldo d’água disponível no solo para o vegetal, ou seja, contabiliza a entrada (precipitação e ou irrigação) e a saída (evapotranspiração), considerando determinada capacidade de armazenamento de água pelo solo.

Medeiros (2016) realizou o cálculo do balanço hídrico (BH) mensal para o município de Matinhas (PB), visando o planejamento da citricultura. O BH resultou em oito meses (agosto a março) de deficiência hídrica com total acumulado de 354,5 mm, ocorrendo excedente hídrico nos meses de junho e julho, evapatranspirando 32\% acima dos índices pluviais registrados, a evaporação anual foi de $906,7 \mathrm{~mm}$.

França et al. (2019) realizaram a análise do BH pelo método de Thornthwaite \& Mather $(1948,1955)$ entre o período de 2000 - 2016 e seu comparativo com o ano de 2016 com o intuito de verificar a deficiência hídrica e a influência do armazenamento d'água no 
solo do município de Serra Talhada - PE. Os elementos meteorológicos mostram que mudanças bruscas ocorreram e que os habitantes deverão mudar de táticas no futuro em relação aos plantios, armazenamento d'água e condições de sobrevivência. Segundo ainda os autores tendência de acréscimo na temperatura e nos índices evaporativos poderão ocasionar eventos extremos de precipitações em curto intervalo de tempo e de alta intensidade.

A insuficiência hídrica é a principal dificuldade a ser confrontado pela humanidade neste século. O uso sustentável d'água não pode ser prioridade apenas do setor agropecuário e das regiões que registram carência d'água, devendo ser prioridade de todos os setores da socioeconômica e regiões (PEDDE et al. 2013). Os fatores climáticos são os principais geradores de flutuações no rendimento de grãos das culturas e das flexibilidades na agropecuária, pois temperatura, umidade e precipitação não podem ser controlados ou modificados pelo homem em grande escala. Cunha et al. (2001).

A precipitação é a exclusiva fonte de fornecimento d'água. Portanto, ao escoar superficialmente a água é barrada em pequenos açudes e utilizada para abastecimento humano e irrigação. Pequena porção d'água pluvial é captada e armazenada em cisternas para fins potáveis. A precipitação é extremamente variável em magnitude quanto na distribuição espaço temporal para qualquer região e, em especial, no Nordeste do Brasil (NEB). (ALMEIDA et al. (2007); ALMEIDA et al. (2004).

A evapotranspiração (ETP) das culturas é variável fundamental no planejamento e execução de manejo na irrigação. Medeiros et al. (2014) estudando o município de Campina Grande - PB observaram que a ETP anual foi de 1.076,8 mm, com variações de 105,4 mm no mês de dezembro a 71,3 mm no mês de agosto. Muitos métodos diferentes de estimar ETP a partir de uma ou mais variáveis foram desenvolvidos de acordo com as condições climáticas locais e disponibilidade de dados adequados (SHUTTLEWORTH, 1993; SINGH et al., 1997; XU et al., 2000; XU et al., 2001).

Objetiva-se realizar o computo do balanço hídrico sequencial (BHS) dos anos 1920 2018 para o município de São Bento do Uma - PE, com o intuito de verificar a contribuição do armazenamento, represamento d'água quanto a ocorrência de deficiência e excesso de água em relação à crise hídrica, além de gerar e disponibilizar subsídios para elaboração de planejamento e projeto da área estudada. 


\section{MATERIAL E MÉTODO}

São Bento do Una localiza-se na mesorregião Agreste e na Microrregião do Vale do Ipojuca do Estado de Pernambuco, a sede municipal localiza-se nas coordenadas geográficas de $08^{\circ} 31^{\prime} 22^{\prime \prime}$ de latitude sul e $36^{\circ} 06^{\prime} 40^{\prime \prime}$ de longitude oeste e altitude de 614 metros. (Figura $1)$.

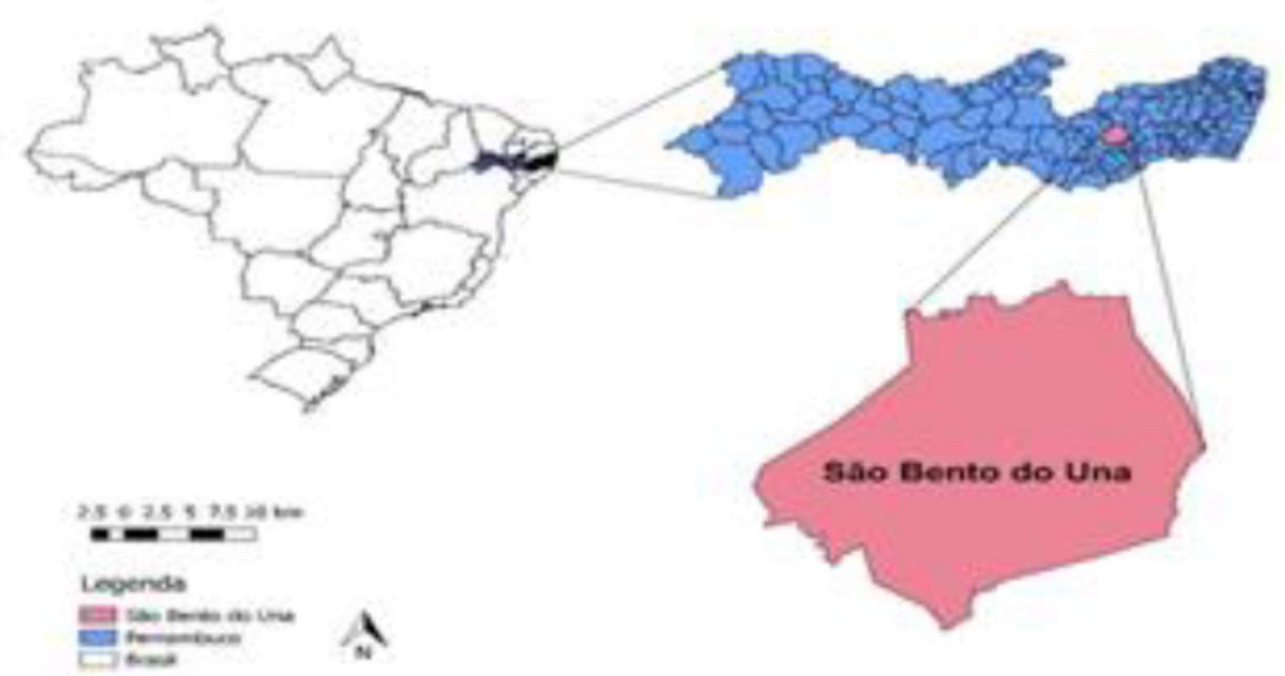

Figura 1. Localização do município de São Bento do Una no Estado do Pernambuco. Fonte: Medeiros, (2020).

O município de São Bento do Una tem clima do tipo "As" (Tropical Chuvoso, com verão seco), segundo a classificação climática de Köppen $(1928,1931)$ e conforme estudos dos autores Medeiros et al. (2018) e Alvares et al. (2014).

Os principais elementos provocadores de chuvas no município o são: contribuição da Zona de Convergência Intertropical, formação dos vórtices ciclônicos de altos níveis, subsídios dos ventos alísios de nordeste no transporte de vapor e umidade condensando-os e formando nuvens que provocam chuvas de forte a moderada intensidade em curto intervalo de tempo, contribuição das formações das linhas de instabilidades, orografia e suas contribuições locais e regionais. Medeiros (2016).

Os dados pluviais médios mensais do município de São Bento do Una foram caracterizando como um período de normal climatológica, onde, empregou-se do software em planilhas eletrônicas, para extrair os valores das médias mensais e anuais da precipitação do período de 1920 a 2018. Os referidos dados foram fornecidos pela Agência de Água e Clima 
do Estado de Pernambuco (APAC, 2019) e pela Superintendência do Desenvolvimento do Nordeste (SUDENE, 1990).

A qualidade dos dados foi examinada, verificando-se, em todas as séries de dados os valores que apresentaram grande discrepância, quando comparados aos observados na própria série de dados do posto, para tanto utilizaram de análise no tocante à sua consistência, homogeneização e no preenchimento de falhas da série, os dados falhos foram preenchidos com os dados de três postos vizinhos: Belo Jardim; Pesqueiro e Cachoeirinha, onde se aplicou a forma:

$$
P x=\frac{1}{3}\left(\frac{N x}{N a} P a+\frac{N x}{N b} P b+\frac{N x}{N c} P c\right)
$$

Em que: Px é o valor pluvial que se deseja determinar; Nx é a precipitação média do posto x; NA, NB e NC são, respectivamente, as precipitações médias observadas dos postos vizinhos A, B e C; PA, PB e PC são as precipitações observadas no instante que o posto $\mathrm{x}$ falhou.

Os dados da temperatura média do ar para a área estudada foram estimadas pelo software Estima_T Cavalcanti et al. $(2006 ; 1994)$. Visto que o referido município não tem equipamentos para se realizar tal observação. O Estima_T é um software para fazer estimativas de temperaturas do ar na Região do do Nordeste do Brasil (NEB). Determinaramse os coeficientes da função quadrática para as temperaturas médias mensais em função das coordenadas locais: latitude, longitude e altitude (CAVALCANTI et al., 2006) dada por:

$$
\mathrm{T}=\mathrm{C}_{0}+\mathrm{C}_{1} \lambda+\mathrm{C}_{2} \varnothing+\mathrm{C}_{3} \mathrm{~h}+\mathrm{C}_{4} \lambda^{2}+\mathrm{C}_{5} \varnothing^{2}+\mathrm{C}_{6} \mathrm{~h}^{2}+\mathrm{C}_{7} \lambda \varnothing+\mathrm{C}_{8} \lambda \mathrm{h}+\mathrm{C}_{9} \varnothing \mathrm{h}
$$

Em que: $\mathrm{C}_{0}, \mathrm{C}_{1}, \ldots ., \mathrm{C}_{9}$ são as constantes; $\lambda, \lambda^{2}, \lambda \varnothing, \lambda \mathrm{h}$ longitude; $\varnothing, \varnothing^{2}, \lambda \varnothing$ latitude; $\mathrm{h}, \mathrm{h}^{2}, \lambda$ $\mathrm{h}, \varnothing \mathrm{h}$ altura.

Também estimaram a série temporal de temperatura, adicionando a esta à anomalia de temperatura do Oceano Atlântico Tropical (SILVA et al., 2006).

$$
\mathrm{T}_{\mathrm{ij}}=\mathrm{T}_{\mathrm{i}}+\mathrm{AAT}_{\mathrm{ij}} \quad \mathrm{i}=1,2,3, \ldots, 12 \quad \mathrm{j}=1950,1951,1952, \ldots .2015
$$

Em que: $\mathrm{i}=1,2,3, \ldots, 12 ; \mathrm{j}=1950,1951,1952,1953, \ldots, 2015$.

Utilizaram-se do método de Thornthwaite \& Mather para o cálculo do balanço hídrico sequencial (BHS) em escala mensal para a área municipal de São Bento do Una, ou seja, o BHS, elaborado a partir das normais climatológicas de temperatura e precipitação média. Essa técnica é utilizada para trabalhar com dados de balanço global d'água do ponto de vista climatológico. Através da contabilização do suprimento natural d'água ao solo, por meio da 
pluviosidade (P), e da demanda atmosférica, pela evapotranspiração potencial (ETP), considerando um nível máximo possível de armazenamento (CAD). O BHS fornece estimativa da evapotranspiração real (ETR), deficiência hídrica (DEF), excedente hídrico (EXC) e armazenamento efetivo d'água no solo (ARM), podendo ser elaborado desde a escala diária até a mensal (CAMARGO, 1971).

Nos cálculos para a obtenção do BHS utilizou-se do valor de CAD representativos dos solos $-\mathrm{CAD}=100 \mathrm{~mm}$ para um solo com alta capacidade de armazenamento no município. $\mathrm{O}$ cálculo do BHS foi computado através de planilha eletrônica elaboradas por Rolim et al. (1998) e adapta por Medeiros (2019).

A Organização Meteorológica Mundial (WMO, 1989) sugerem que em estudos comparativos de clima, deve-se serem utilizadas das séries médias para períodos com mais de 30 anos de observações, para tanto os dados precisam ter consistência e homogeneidade na sua comparação entre seus valores analisados.

\section{RESULTADOS E DISCUSSÕES}

As oscilações pluviais da área estudada podem ser visualizadas na Tabela 1, a qual fornece subsídios para delimitação dos parâmetros estatísticos básicos. A quadra chuvosa inicia-se em fevereiro e prolonga-se até julho com média de 74,6 mm. O período seco corresponde os meses de agosto a janeiro com índices pluvial médio de 26,3 mm. O trimestre chuvoso centra-se nos meses de março, abril e maio com precipitação média de 85,4 mm, os meses secos são setembro, outubro e novembro com um índice pluvial médio de 20,2 $\mathrm{mm}$. A precipitação média anual de $605,4 \mathrm{~mm}$. A precipitação máxima absoluta registrada foi de 1079,9 mm no ano de 1966, suas flutuações máximas absolutas oscilaram entre 105,7 mm no mês de agosto do ano de 1922 a 332,5 mm no mês de abril do ano de 1985. As flutuações mínimas absolutas fluíram entre 0,1 mm no ano de 1949 a 9,4 mm no mês de julho de 1930 . A precipitação mínima absoluta anual foi de $227,8 \mathrm{~mm}$ no ano de 2012 . A variabilidade da mediana oscila entre 0,0 mm nos meses de novembro e dezembro do ano de 1970 a 104,3 mm no mês de março do ano de 1979, com um total anual de 486,6 mm no referido ano descrito. (Medeiros, 2019). Os valores máximos e mínimos absolutos tem possibilidade de retorno entre seis a dezoitos meses. Trabalhos semelhantes foram desenvolvidos por Marengo et al. (2007; 2015) corroboram com os resultados discutidos. 
Tabela 1. Parâmetros estatistico da pluviometria (mm) entre os anos de 1920-2018 no município de São Bento do Una - PE.

\begin{tabular}{llllllllllllll}
\hline $\begin{array}{l}\text { Parâmetro } \\
\text { meses }\end{array}$ & Jan & Fev & Ma1 Abr & Mai & Jun & Jul & Ago & Set & Out & Nov & Dez anual \\
\hline Média & 39,8 & 53,6 & $91,(84,2$ & 81,0 & 73,7 & 64,0 & 32,9 & 20,0 & 19,2 & 21,4 & 24,6 & 605,4 \\
Mediana & 63,1 & 13,8 & 104 & 62,7 & 49,3 & 47,9 & 97,6 & 23,4 & 6,1 & 18,4 & 0,0 & 0,0 & 486,6 \\
Desv. Pad41,5 & 49,2 & $70,<61,9$ & 51,3 & 47,5 & 36,9 & 21,1 & 18,5 & 27,0 & 36,2 & 35,8 & 190,8 \\
Coef. Var.1,04 & 0,92 & 0,$7 ; 0,74$ & 0,63 & 0,64 & 0,58 & 0,64 & 0,93 & 1,41 & 1,69 & 1,45 & 0,32 \\
Prec máx 217,2 & 233,7 & 305332,5 & 263,6 & 292,8 & $189,8105,7112,6$ & 150,3 & 287,5 & $259, \ldots$ & 1079,9 \\
Prec mín 0,0 & 0,5 & 0,1 & 4,6 & 0,8 & 4,0 & 9,4 & 2,4 & 0,0 & 0,0 & 0,0 & 0,0 & 227,8
\end{tabular}

LEGENDA: Desv. Pad. = Desvio padrão; Coef. Var. = Coeficiente de Variância; Prec máx $=$ Precipitação máxima absoluta; Prec mí = Precipitação mínima absoluta. Fonte: Medeiros, (2020).

Galvani (2011) em seus estudos sobre o desvio padrão mostrou que é extraordinária para terem-se informações do "grau de dispersão dos valores em relação ao valor médio". O coeficiente de variância que é utilizado para fazer comparações em termos relativos e expressa "a variabilidade de cada conjunto de dados normalizada em relação à média, em porcentagem."

Sousa et al. (2010) mostraram que as informações dos elementos climáticas de uma determinada região é imprescindível para que se possam elaborar estratégias visando diretrizes acertadas sobre os recursos naturais, buscando achar por uma ampliação sustentável e aplicando novas técnicas agropecuárias viáveis e seguras para os biomas locais.

Na Tabela 2 observam-se os parâmetros estatistico da temperatura média do ar $\left({ }^{\circ} \mathrm{C}\right)$ entre os anos de 1920-2018 no município de São Bento do Una - PE. A temperatura média anual é de $22{ }^{\circ} \mathrm{C}$ e suas oscilações mensais fluem entre $19,5^{\circ} \mathrm{C}$ no mês de julho a $23,5^{\circ} \mathrm{C}$ nos meses de dezembro e janeiro.A mediana anual registra $22,3{ }^{\circ} \mathrm{C}$ e suas oscilações mensais registra-se entre $19,7{ }^{\circ} \mathrm{C}$ a $24,3{ }^{\circ} \mathrm{C}$ no mês de dezembro. $\mathrm{O}$ desvio padrão fluem entre $0,3{ }^{\circ} \mathrm{C}$ a $0,4^{\circ} \mathrm{C}$ com índice anual de $0,3{ }^{\circ} \mathrm{C}$. Os coeficintes de variância fluem entre $0,012{ }^{\circ} \mathrm{C}$ no mês de abril a $0,016{ }^{\circ} \mathrm{C}$ no mês de dezembro com um coeficiente anual de $0,012{ }^{\circ} \mathrm{C}$.

Tabela 2. Parâmetros estatistico da temperatura média do ar $\left({ }^{\circ} \mathrm{C}\right)$ entre os anos de 1920-2018 no município de São Bento do Una - PE. 


\begin{tabular}{lcccccccccccccc}
\hline $\begin{array}{l}\text { Parâmetros } \\
\text { meses }\end{array}$ & Jan & Fev & Mar & Abr & Mai & Jun & Jul & Ago & Set & Out & Nov & Dez anual \\
\hline Média & 23,5 & 23,4 & 23,2 & 22,8 & 21,6 & 20,4 & 19,5 & 19,7 & 20,8 & 22,3 & 23,2 & 23,5 & 22,0 \\
Mediana & 23,7 & 23,6 & 23,3 & 23,0 & 21,9 & 20,7 & 19,7 & 19,9 & 21,1 & 22,8 & 23,8 & 24,3 & 22,3 \\
Desv.pad & 0,4 & 0,3 & 0,3 & 0,3 & 0,3 & 0,3 & 0,3 & 0,3 & 0,3 & 0,3 & 0,4 & 0,4 & 0,3 \\
Coef.Var. & 0,015 & 0,014 & 0,013 & 0,012 & 0,013 & 0,014 & 0,014 & 0,014 & 0,014 & 0,014 & $0,01:$ & 0,016 & 0,012 \\
Temp.max & 24,6 & 24,5 & 24,2 & 23,6 & 22,4 & 21,0 & 20,1 & 20,4 & 21,6 & 23,2 & 24,2 & 24,6 & 22,6 \\
Temp. mim & 22,7 & 22,8 & 22,7 & 22,3 & 21,0 & 19,8 & 18,9 & 19,2 & 20,2 & 21,6 & 22,4 & 22,4 & 21,4 \\
\hline
\end{tabular}

LEGENDA: Desv. Pad. $=$ Desvio padrão; Coef. Var. $=$ Coeficiente de Variância; Temp max $=$ temperatura máxima absoluta; Temp mín = temperatura mínima absoluta.

Fonte: Medeiros, (2020).

A variabilidade da temperatura máxima absoluta oscilaram entre $20,1{ }^{\circ} \mathrm{C}$ no mês de julho a $24,6{ }^{\circ} \mathrm{C}$, registrando $22,6{ }^{\circ} \mathrm{C}$ no valor anual.A temperatura máxima da máxima absoluta registrada foi de $32,4^{\circ} \mathrm{C}$ no ano de 1997 e a temperatura máxima da mínima foi de $24,8{ }^{\circ} \mathrm{C}$ no ano de 1956. A temperatura mínima anual registrou-se no ano de 1960 com 21,4 ${ }^{\circ} \mathrm{C}$. A temperatura mínima máxima foi de $20,5{ }^{\circ} \mathrm{C}$ no ano d 1998 ocorrida nos meses de janeiro e fevereiro.As temperatura mínimas das mínimas registrados foi de $15,8^{\circ} \mathrm{C}$ no mês de julho do ano de 2016. As oscilações térmicas mensais e anuais estão interligadas aos fenômenos de escala local, regional e a orografia. Trabalhos como o dos autores (MARENGO et al., 2015; 2008; 2007; MEDEIROS et al., 2018) vem a corroboram com os resultados deste estudo.

Ometto (1981) e Pereira et al. (2002) mostraram que as flutuações dos índices térmicos máximos e mínimos do ar permanecem integrados à quantidade da energia solar recebida, cobertura de nuvem, umidade relativa do ar e do solo, vento e dos parâmetros orografia, altitude e latitude local.

$\mathrm{O}$ BH e o BHS podem ser utilizados em planejamento agroflorestal e estudos de vocação territorial, como por exemplo: identificar datas de semeadura com menor ocorrência média de dias com excedente hídrico para culturas (LUCAS et al., 2015); dar subsídio ao planejamento agrícola de uma região pela espacialização das deficiências hídricas em função da CAD (CARDOSO, 2005; FREITAS et al., 2011); estudos de viabilidade de empreendimentos agroflorestais (ORLANDINI et al., 2011); estudos hidro agrícolas e ambientais de bacias hidrográficas (SANTOS et al., 2013); Estudos de alterações climáticas (GARCIA, 2010; COUTINHO et al., 2012). Podem também subsidiar a gestão das atividades 
agropecuárias e turísticas, identificando as épocas mais favoráveis às atividades, Zoneamento Agrícola de Risco Climático (NEVES et al., 2011), e estudos relacionados a aptidões e zoneamentos agrícolas.

O cômputo do BHS corresponde ao período de 1920 - 2018 para o município de São Bento do Una onde se busca compreender suas flutuações e variabilidades, estando representados nas Figuras de 2 a 7 . Após a realização do computo do BHS separou-se os elementos temperatura média, precipitação, evaporação, evapotranspiração e elaboraram-se os gráficos das deficiências e excedentes hídricos para melhor visualizarmos suas flutuações e compreendermos as oscilações decadais como estão representados a seguir.

Salienta-se que para cada década discutida e apresentada os valores médios máximos e mínimos térmicos não se detalharam as flutuações mensais ano a ano visto que o texto ficaria intenso e cansativo para sua leitura. As riquezas de detalhes poderão ser observadas na Figura 2.

Na Figura 2 tem-se as oscilações da temperatura média do ar entre os anos de 1950 2018 e das médias decadais (1950-1959; 1960-1969; 1970-1979; 1980-1989; 1990-1999; 2000-2009; 2010-2018) no município de São Bento do Una - PE.

$\mathrm{Na}$ década 1950 - 1959 a temperatura média anual registrada foi de $21,8{ }^{\circ} \mathrm{C}$ e as oscilações da tempertura máxima $23,9^{\circ} \mathrm{C}$ no ano de 1958 e da temperatura mínima de $19{ }^{\circ} \mathrm{C}$ regsitradas nos anos de 1955 e 1956. Na década de 1960 -1969 registrou-se um aumento na temperatura média de $0,1{ }^{\circ} \mathrm{C}$ comparada com a década anterior. A temperatura máxima da década de 1960-1969 foi de 23,9 ${ }^{\circ} \mathrm{C}$ registrada no ano de 1969 e a temperatura mínima ocorreu no ano de 1963 com $19,8{ }^{\circ} \mathrm{C}$. Com uma temperatura média de $21,8{ }^{\circ} \mathrm{C}$ e sua temperatura máxima de $24,2{ }^{\circ} \mathrm{C}$ no ano de 1972 e temperatura mínima de $19,9{ }^{\circ} \mathrm{C}$ no ano de 1973 foram registradas na década de 1970 - 1979. Comparando-se os aumentos decadais climáticos registrados na decada de 50 e 70 temperatura média iguais e aumento de $0,1^{\circ} \mathrm{C}$ na década de 60 . A década de 80 registrou temperatura média de $21,9{ }^{\circ} \mathrm{C}$, com temperatura máxima nos anos de 1982 e $1983\left(24,3{ }^{\circ} \mathrm{C}\right)$. A temperatura mínima decadal $\left(19,4^{\circ} \mathrm{C}\right)$ registrou-se nos anos de $1981 ; 1984$ e 1988 . Com $22,2{ }^{\circ} \mathrm{C}$ de temperatura média ocorrida na década de 90 e com $24,6^{\circ} \mathrm{C}$ de temperatura máxima nos anos1987/1998 e com temperatura mínima de $19,5^{\circ} \mathrm{C}$ no ano de 1999 . A década 2000 apresentou temperatura média de $22,1^{\circ} \mathrm{C}$ e suas temperatura máxima e mínimas registrada foram de: $24,2{ }^{\circ} \mathrm{C}$ no ano de 2002 e $19,4{ }^{\circ} \mathrm{C}$ (2009), respectivamente. Na década 2010 as temperaturas máximas e mínimas registradas 
ocorreram nos anos de $2017\left(23,8^{\circ} \mathrm{C}\right)$ e $19,2{ }^{\circ} \mathrm{C}$ no ano de 2016 com média décadal de 22,0 ${ }^{\circ} \mathrm{C}$.

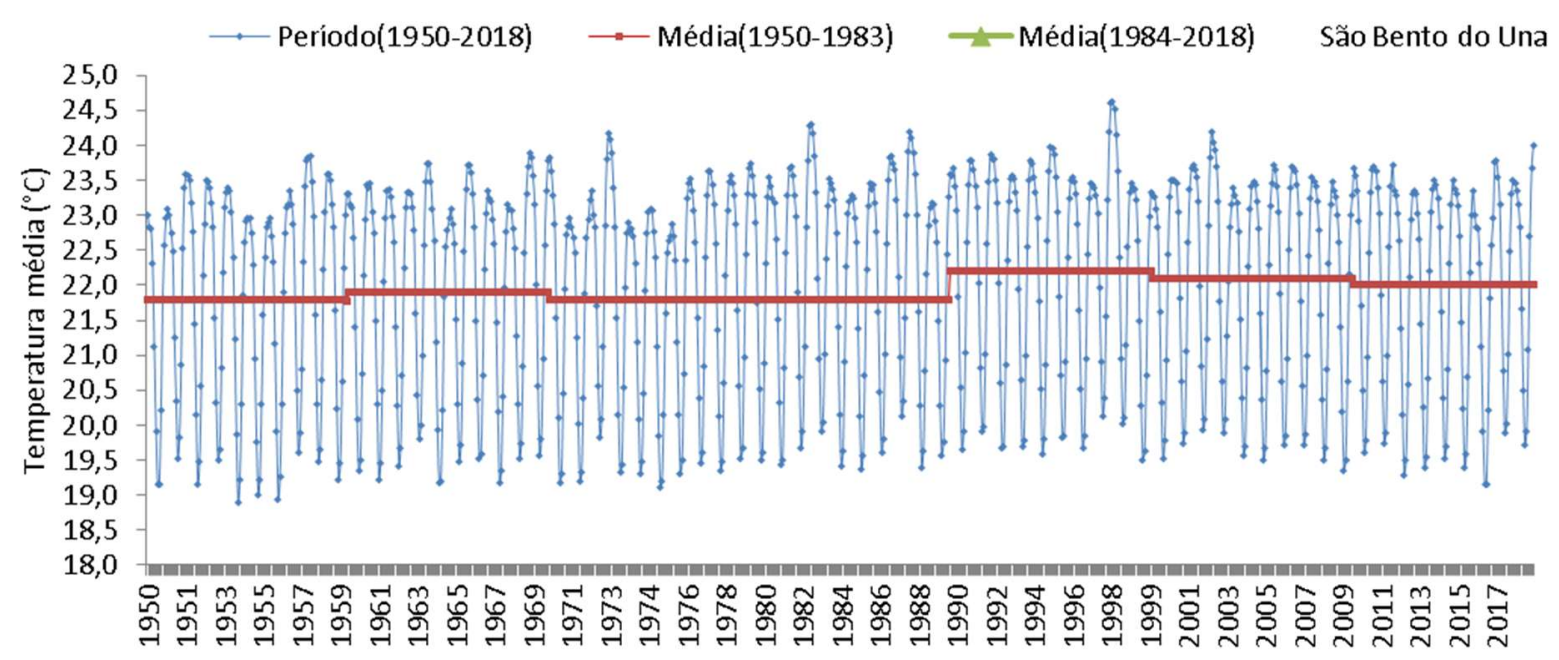

Figura 2. Variabilidade da temperatura média do ar entre os anos de 1950 - 2018 e das médias decadais (19501959; 1960-1969; 1970-1979; 1980-1989; 1990-1999; 2000-2009; 2010-2018) no município de São Bento do Una - PE.

Fonte: Medeiros, (2020).

Tais oscilações verificadas vem a serem relatadas nos estudos de Marengo et al. $(2015 ; 2010$ e 2007) e Medeiros et al. (2018).

Barbieri (2007) e Sachs (2015) afirmaram que nas últimas quatro décadas, os estudiosos compreenderam que a finitude dos recursos naturais coligada com a fragilidade dos ecossistemas do planeta Terra não suportaria o ritmo de crescimento econômico imposto pela humanidade. Marengo et al. (2011) explicaram que o acréscimo da temperatura influência na perda de umidade do solo, tendo como consequência o aumento dos poderes evaporativos locais. Estes estudos corroboram com os resultados da pesquisa em discussões.

O BHS fornecem informações detalhadas das variabilidades térmicas do período estudado gerando informações importantes aos tomadores de decisões governamentais e aos elaboradores de projetos pecuários, agrícolas, agronegócios, entre outras áreas e para um desenvolvimento sustentável da produção avícola em São Bento do Una.

Na Figura 3 observam-se as variabilidade da precipitação entre os anos de 1950-2018 e das médias decadais $(1950-1959 ; 1960-1969 ; 1970-1979 ; 1980-1989 ; 1990-1999 ; 2000-$ 2009; 2010-2018) no município de São Bento do Una - PE. Com média pluvial decadal (1950-1959) de 38,6 mm e suas variabilidades máximas e mínimas de 226,7 mm (1957) a 0,0 $\mathrm{mm}$ em todas os anos da década. Na década 60 registrou-se média decadal de $58,1 \mathrm{~mm}$ e a 
precipitação máxima ocorreu no ano de 1966 com 286,2 mm e a precipitação mínima entre os anos de 1960; 1967; 1968 e 1969 sem ocorrencias de índices pluviais. Os índices pluviais mínimos só registrou-se no ano de 1979, a precipitação máxima ocorrida foi de $254,3 \mathrm{~mm}$ no ano de 1971 com média de $54 \mathrm{~mm}$ para a dácada de 70 . A decada 80 registrou precipitação média de 53,2 mm e os valores máximos pluviais registrado no ano de $1985 \mathrm{com} 332,5 \mathrm{~mm}$ e os mínimos valores $(0,0 \mathrm{~mm})$ nos anos de $1980 ; 1984 ; 1985 ; 1989$. Na década 90 a média pluvial foi de 46,1 mm sua precipitação máxima ocorreu no ano de 1991 com 188,2 mm, os anos de 1990; 1993 e 1994 registrou índices pluviais mínimos de 1,6 mm; 2,0 e 2,6 mm respectivamente. A década 2000 registrou indices pluviais máximo no ano de 2008 com 264,1 mm e chuvas mínimas nos demais anos exceto o ano de 2000 que seu valor foi $0,0 \mathrm{~mm}$, ou seja sem ocorrencia de chuvas. Na década 2010 a precipitação média foi de $44,6 \mathrm{~mm}$, chuva mínima de 0,4 mm em 2016 e nos demais anos sem ocorrencia de registro a precipitação máxima foi de $292,8 \mathrm{~mm}$ no ano de 2010 .

Um resumo dos valores médios dos índices pluviais por década foi: 50 com 38,6 mm; 60 com 58,1 mm; 70 com 54,0 mm; 80 com 53,2 mm; 90 com 46,1 mm; 2000 com 59,1 mm e 2010 com 44,6 mm. Estudo como o do IPCC (2014 e 2007); Holanda et al. (2016) e Marengo et al. (2010) contribuem para os resultados dos valores aqui encontrados.

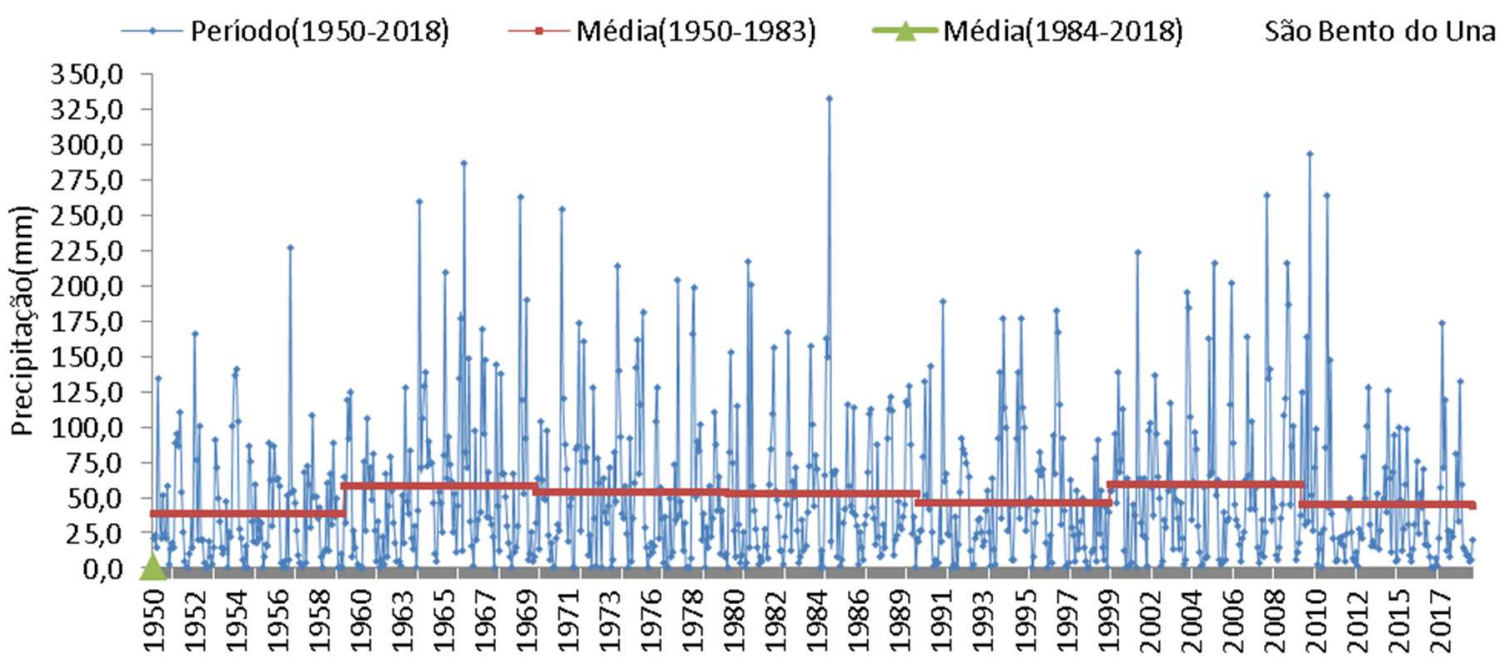

Figura 3. Variabilidade da precipitação entre os anos de 1950-2018 e das médias decadais (1950-1959; 19601969; 1970-1979; 1980-1989; 1990-1999; 2000-2009; 2010-2018) no município de São Bento do Una - PE. Fonte: Medeiros, (2020).

O consumo de quanto realmente está sendo evapotranspirado é expresso pela evapotranspiração potencial (ETP), a qual se comporta semelhante à distribuição pluvial. 
Estas flutuações ocorrem devido às oscilações entre os períodos seco e chuvoso, lembra-se ainda que os movimentos dos fatores provocadores e/ou inibidores de chuvas depende exclusivamente dos elementos de larga, meso e grande escala, assim como das contribuições dos efeitos locais, por exemplo, o posicionamento da Zona de convergência Intertropical; a atuação dos Vórtices Ciclônico de Altos Níveis, o dipolo, as intensidades dos ventos alísios, entre outros elementos. Medeiros (2018).

Nos anos 1950 a ETP média foi de $88,5 \mathrm{~mm}$ suas oscilações máximas registrada no ano 1958 com 1097,2 mm e seus máximos e mínimos mensais foram de: 116,1 mm em janeiro a 64,7 mm em julho. Na década de 1950 evapotranspirou 129,3\% acima do valor pluvial. Na década de 1960 evapotranspirou 54,4\% acima do valor pluvial, com ETP máxima no ano de 1969 totalizando $1120,7 \mathrm{~mm}$ com máximo mensal de $116,7 \mathrm{~mm}$ no mês de janeiro e seu mínimo de 65,4 mm em julho. A década 1970 a ETP máxima anual foi de 1114,4 mm com o máximo mensal de $120 \mathrm{~mm}$ no mês de dezembro a $67,6 \mathrm{~mm}$ em julho. Evapotranspirou $64,6 \%$ acima do valor pluvial decadal. O ano de 1983 registrou total anual de 1137,7 mm com um máximo mensal de 121,9 mm no mês de janeiro e seu mínimo de 68,5 mm em julho. Evapotranspirou na década de 1980, 72,7\% acima do valor pluviométrico. A década 1990 registrou média de 93,2 $\mathrm{mm}$, portanto evapotranspirou 102,2\% acima do valor pluvial. No ano de 1998 a ETP anual foi de 1161,8 mm com 125,9 mm no mês de janeiro e 69,4 mm no mês de julho. O ano de 2002 registrou um total de ETP de 1141,8 mm e suas oscilações máximas e mínimas foram de $120,4 \mathrm{~mm}$ no mês de dezembro a $68,4 \mathrm{~mm}$ em julho. A média decadal foi de 91,6 mm. Evapotranspirou 55\% acima do valor pluvial na década estudada. Na década de 2010 os índices evapotranspirados foram de 100,9\% acima do índice pluvial. O ano de 2011 caracterizado com o de alto índice evapotranspirados registrando ETP anual de 1114,7mm e seus valores extremos de $114,5 \mathrm{~mm}$ no mês de dezembro a $67 \mathrm{~mm}$ em julho 


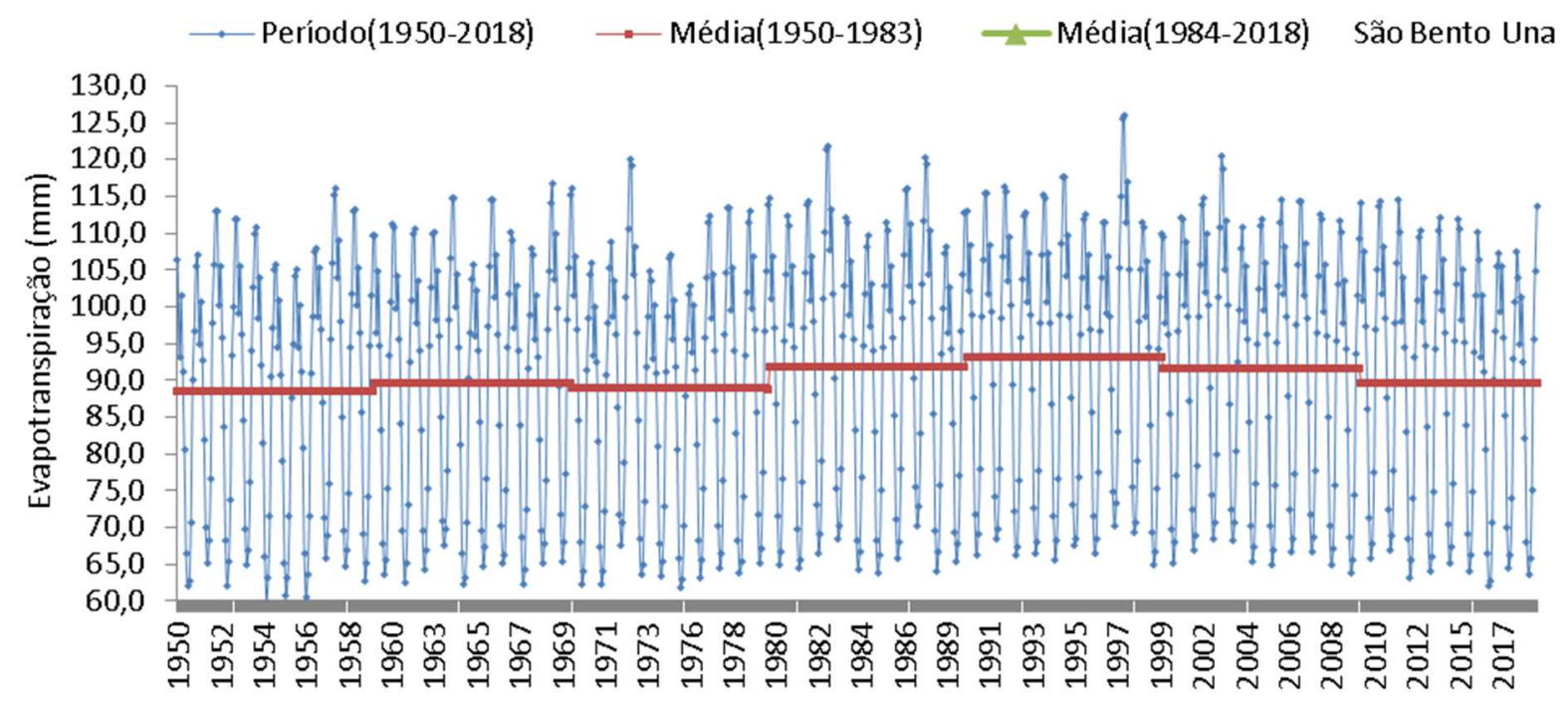

Figura 4. Variabilidade da evapotranspiração entre os anos de 1950-2018 e das médias decadais (1950-1959; 1960-1969; 1970-1979; 1980-1989; 1990-1999; 2000-2009; 2010-2018) no município de São Bento do Una PE.

Fonte: Medeiros, (2020).

Marengo (2012) mostrou que a região do NEB distinguir-se naturalmente pelo alto potencial evaporativo d'água em desempenho da ampla disponibilidade de energia solar e das altas oscilações das temperaturas e das baixas coberturas de nuvens. Aumentos de temperatura associados à mudança de clima decorrente do aquecimento global, independente do que possa vir a ocorrer com as chuvas, já seriam suficientes para causar maior evaporação dos lagos, açudes e reservatórios e maior demanda evaporativa das plantas. Isto é, a menos que haja aumento de chuvas, a água se tornará um bem mais escasso, com sérias consequências para a sustentabilidade do desenvolvimento regional de local.

Sales (2003) garantiu que a ETR, ao contrário da ETP, satisfaz a uma disponibilidade total d'água, simulando o volume que é retirado do sistema pela evapotranspiração e que é usada na produção primária pelos vegetais. Considerando ser a EVR aquela que ocorre nas condições reais às quais o vegetal está submetido, não existindo disponibilidade hídrica satisfatória e vegetação uniforme sobre a superfície, constata-se uma relação direta entre os índices pluviais e a EVR, sendo que os menores índices de EVR relacionam-se aos baixos índices pluviais e os maiores índices de EVR a uma precipitação elevada. Esta afirmação de Sales reafirma os valores das oscilações encontrados neste artigo.

Nobre et al. (2005) afirmaram que um aumento na temperatura do ar eleva os índices evaporados e evapotranspirativos acarretando em deficiência hídrica acentuado e alterações 
no ciclo hidrológico. Este resultado demonstrado pelos autores vem a corroborar com o estudo em desenvolvimento.

Na Figura 5 observam-se as variabilidades das evaporações entre os anos de 19502018 e das médias decadais (1950-1959; 1960-1969; 1970-1979; 1980-1989; 1990-1999; 2000-2009; 2010-2018) no município de São Bento do Una - PE. Na década 1950 o maior poder evaportivo foi o do ano de 1954 com 557,9 mm, a máxima e mínima registrou-se nos meses de março com 100,3 mm e no mês de dezembro com 2,9 mm, Precipitou 0,77\% acima do índice evaporativo. Na decada 1960 a EVR foi abaixo do índice pluvial 9\%, o ano de 1964 registrou EVR mensal de 884,8 mm com seus valores máximos e mínimos de 104,5 mm em janeiro e 26,1 mm em novembro. Com média decadal de 48,4 $\mathrm{mm}$ e com 1\% de EVR abaixo do índice pluvial, tendo como o ano de maior poder evaporativo 1972 que totalizou 751,1 mm com seu valor máximo de 96,3 mm registrado no mês de abril e com 5,2 $\mathrm{mm}$ de registro de EVR mínimo no mês de janeiro. No ano de 1985 a EVR anual totalizou 732,8 mm com 103,1 mm no mês de março a 9,3 mm em janeiro, choveu acima dos índices evaporativos 4,8\%. Com 4,7\% de poder evaporaivo abaixo dos índices pluviais foi a década de 1990. O ano de 1995 registrou 787,8 mm com máximo de 109,8 mm no mês de março e 11,3 mm em dezembro. Na década 2000 o valor evaportivo foi abaixo dos índices pluviais em 9,45\%, o ano de 2004 registrou EVR total de 791,1 mm com seu máximo de 111,6 mm no mês de marcoe seu mínimo no mês de novembro de $10,6 \mathrm{~mm}$. O ano de 2010 registrou-se alto índices evaporativo da década totalizando $802,2 \mathrm{~mm}$ com seu máximo de $114,2 \mathrm{~mm}$ em janeiro a 26,1 $\mathrm{mm}$ em dezembro, choveu acima dos índices evaportivos 7,5\%.

Com estes índices pluviais acima do poder evaporativos as condições climaticas não foram necessárias e suficientes para estabelecer um equílibro no BHS e armazenar d'água. 


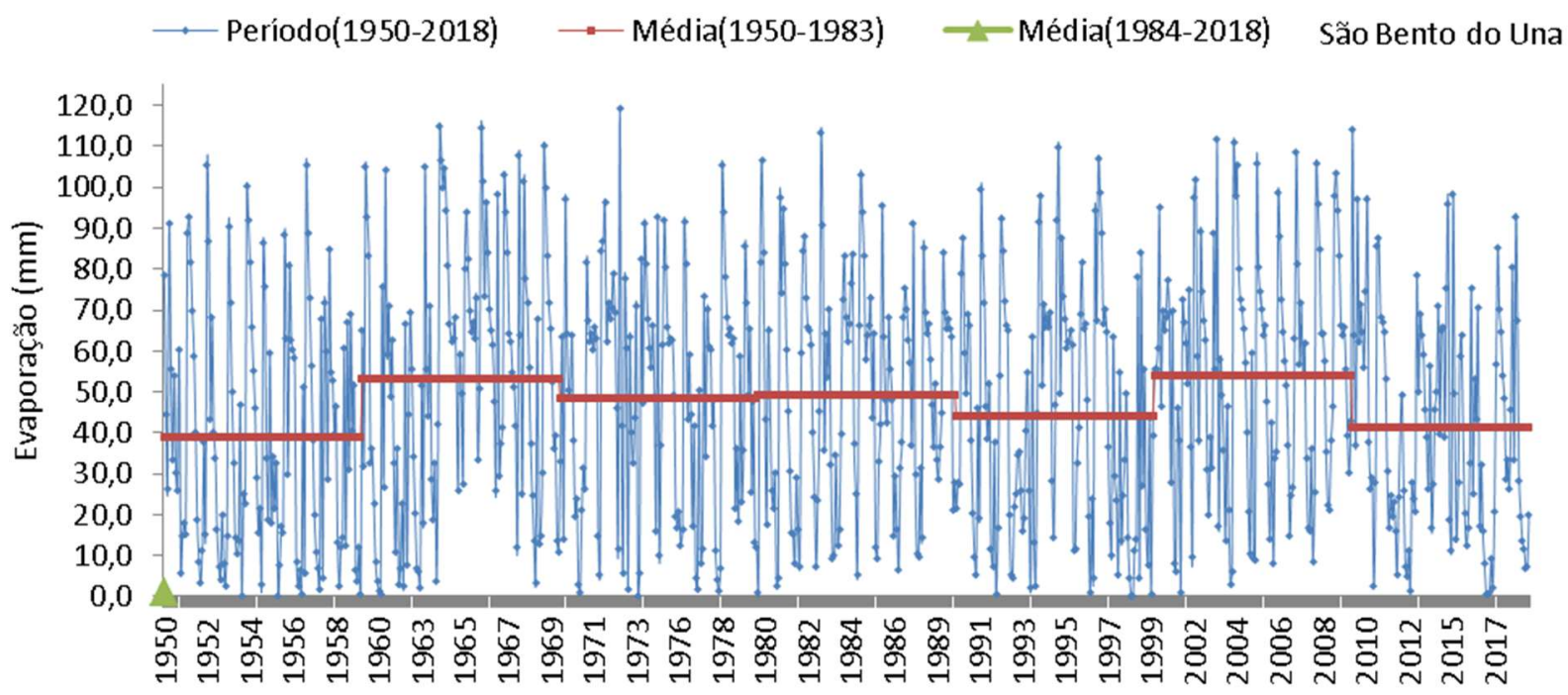

Figura 5. Variabilidade da evaporação entre os anos de 1950-2018 e das médias decadais (1950-1959; 19601969; 1970-1979; 1980-1989; 1990-1999; 2000-2009; 2010-2018) no município de São Bento do Una - PE. Fonte: autor (2020).

Souza et al. (2006) explicaram que a disponibilidade de água no solo é influenciada pelas flutuações térmicas e a distribuição espaço temporal das precipitações. A distribuição da deficiência hídrica pode ser observada na Figura 6. Na década 1950 as DEF registraram-se entre 9 a 12 meses. As deficiências máximas ocorreram entre os meses de setembro, novembro, dezembro e janeiro, já as DEF mínimas registradas foram nos anos de 1955 e 1956 nos meses de setembro e dezembro, a década de 50 teve média de 49,5 mm. A década 60 registou média de 36,5 $\mathrm{mm}$ com deficiências fluindo entre 7 a 11 meses, as DEF máximas oscilaram entre 70,3 mm no mês de novembro de 1964 a 733,4 mm no mês de dezembro do ano de 1962. A década 70 apresentou DEF hídrica registrada entre 7 a 11 anos com oscilações nos meses de janeiro e dezembro. A DEF hídrica máxima total foi de 618,8 mm em 1976 e 97,2 $\mathrm{mm}$ no ano de 1975 com média decadal de 40,5 $\mathrm{mm}$. Com média de 47,5 $\mathrm{mm}$ e com oscilações ocorridas ente 7 a10 meses, a década 1980 registrou a maior DEF no ano de 1980 com 569,4 mm e sua mínima DEF de 84,8 mm em 1989. Com média de 49,2 mm e DEF máxima de 908 mm no ano de 1998 e DEF mínima de 102,1 mm em 1993. As oscilações das DEF foram verificadas entre 8 e 12 meses durante toda a década de 90 . Na década 2000 registraram-se DEF hídrica nos meses de novembro, dezembro e janeiro fluindo entre 6 a 11 meses. A DEF total 2001 foi de $637,8 \mathrm{~mm}$ e a mínima total de 71,2 $\mathrm{mm}$ em 2009, sua média decadal foi de 37,6 mm. Na década 2010 as DEF hídricas registraram-se entre 8 a 12 meses. DEF máxima de 834,2 mm no ano 2012 e mínima de 13,9 mm no mesmo ano. Estas 
deficiências estão relacionadas às flutuações atmosféricas provocadoras ou inibidoras de chuva na região. Salienta-se ainda que as incidências pluviais ocorridas não foram suficientes para repor a capacidade de campo $(\mathrm{CAD}=100 \mathrm{~mm})$.

Camargo (1971) mostrou que para avaliar se uma região tem deficiência ou excesso de água durante o ano devem-se considerar dois elementos, a precipitação, responsável pelo aumento da umidade do solo, e a evapotranspiração, responsável pela sua retirada de umidade no solo.

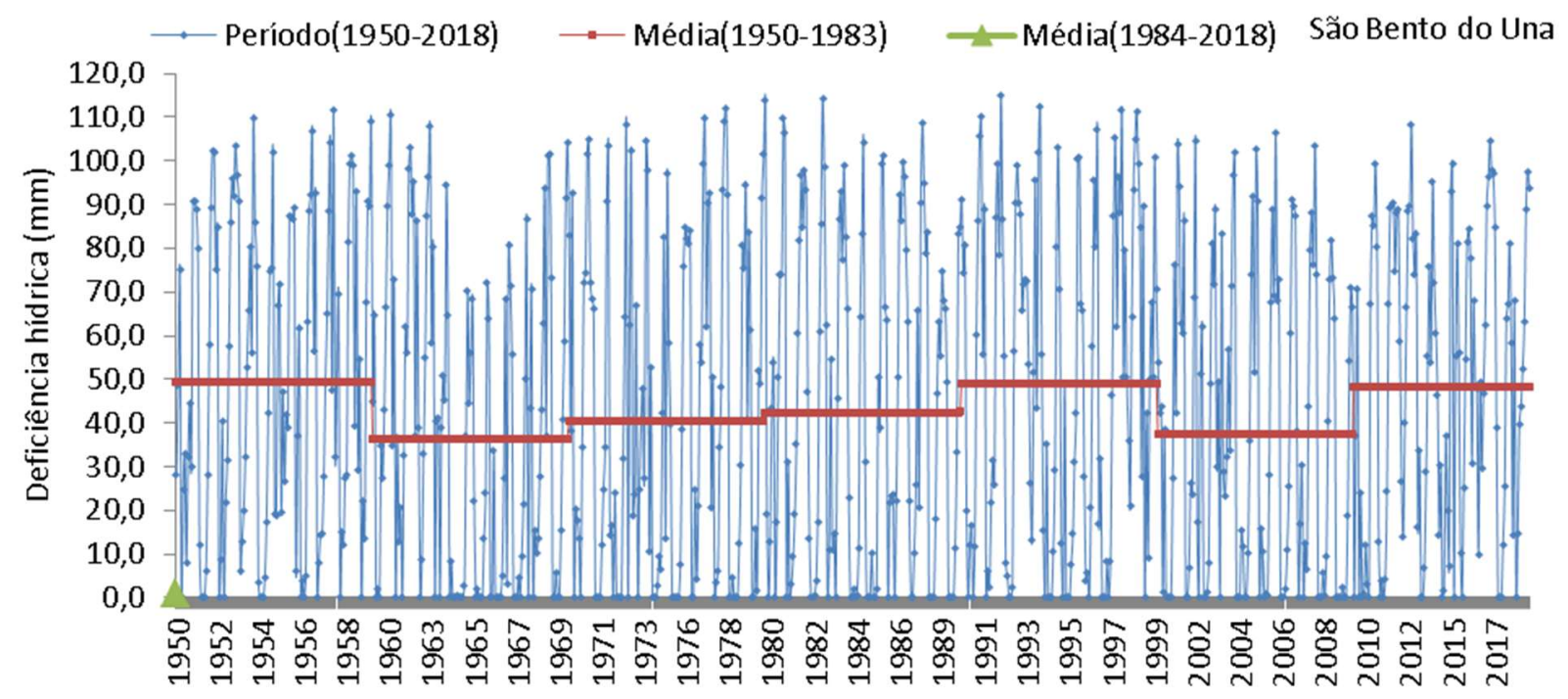

Figura 6. Variabilidade da deficiência hídrica entre os anos de 1950-2018 e das médias decadais (1950-1959; 1960-1969; 1970-1979; 1980-1989; 1990-1999; 2000-2009; 2010-2018) no município de São Bento do Una PE.

Fonte: Medeiros, (2020).

Ortolandi (2011) afirmou que as flutuações das DEF, integradas aos períodos de estiagem prolongada durante o período chuvoso, é uma das causas das reduções de safras de grãos no Brasil e para que hajá uma redução nas suas perdas para os agricultores, tornou-se imprescindível amoldar-se, quantificar e mapear as áreas mais adequadas ao plantio das culturas de sequeiro, levando-se em consideração as condições climáticas e a distribuição pluvial.

Na Figura 7 observam-se as variabilidades dos excedentes hídricos entre os anos de 1950-2018 e das médias decadais (1950-1959; 1960-1969; 1970-1979; 1980-1989; 1990 1999; 2000-2009; 2010-2018) no município de São Bento do Una - PE. Os totais anuais de 1950-1959 fluiram de 409,3 mmno ano de 1954 a 708,7 $\mathrm{mm}$ no ano de 1953, com média decadal de $0,5 \mathrm{~mm}$. Na decada 60 a média foi de $4,9 \mathrm{~mm}$ o excedente hídrico mínimo foi de 
118,9 mm no ano de 1964 e o máximo excedente registrou-se no ano de $1962 \mathrm{com}$ 728,6 mm. Com o máximo de excedente hídrico no ano de 1977 com 611,8 mm e seu mínimo de 331,1 no ano de 1975 e com média decadal de 5,6 $\mathrm{mm}$ para a década 70 . A década 80 registrou média de 3,8 mm e suas oscilações extremas foram de 591,4 mm em 1983 e 320,4 mm em 1985. Na década 90 o excedentes hídricos oscilou entre 330,7 mm em 1995 a 858,6 mm em 1998 com média de 2,2 mm. Com média de 5,1 mm e suas flutuações mínimas e máximas fluiram em 341,2 mm em 2002 a 594,5 mm em 2003 foram os comportamento dos excedentes hídricos na decada 2000. A década 2010 registrou excedente hidrico máximo de 815,6 mm no ano de 2012 e $281,1 \mathrm{~mm}$ em 2010 com média de $3,1 \mathrm{~mm}$.

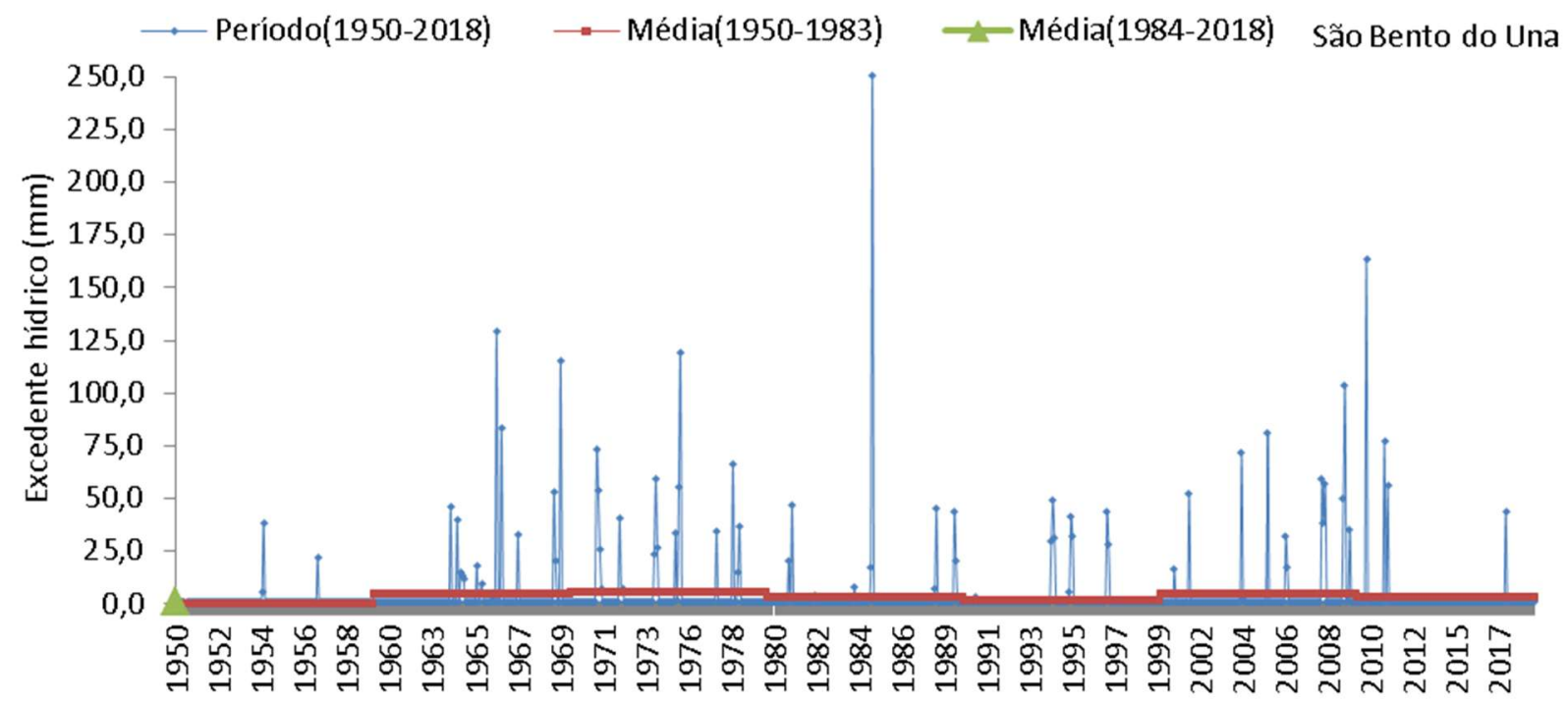

Figura 7. Variabilidade do excedente hídrico entre os anos de 1950-2018 e das médias decadais (1950-1959; 1960-1969; 1970-1979; 1980-1989; 1990-1999; 2000-2009; 2010-2018) no município de São Bento do Una PE.

Fonte: Medeiros, (2020).

As variabilidades mensais e irregulares (Figura 7) que se registrou nos excedentes hídricos podem ser verificadas nos anos de: 1954; 1957; 1963; 1964; 1965; 1966; 1967; 1969; $1971 ; 1972 ; 1974 ; 1975 ; 1977 ; 1978 ; 1981 ; 1985 ; 1988$ 1989; 1994; 1995; 1997; 2000; 2001; 2002; 2004; 2005; 2006; 2008; 2009; 2010 e 2011.

Devido às irregularidades interanuais pluviométricas registradas na área de estudo destacam-se as oscilações dos excedentes hídricos os quais em alguns anos não alcançaram a capacidade de campo e suas contribuições para o armazenamento e represamento de água. 
A limitação dos recursos hídricos na atualidade é importante condicionante ao desenvolvimento socioeconômico, acarretando inúmeros desafios ao planejamento e gerenciamento deste recurso (SOUSA et al., 2015).

Marengo et al. (2012) asseguraram que um aquecimento nas áreas semiáridas poderá ocasionar elevados eventos extremos, como secas ou enchentes ainda mais demandadas e acentuadas, desta forma os informes aos gestores públicos são voltadas a uma visão do planejamento amplo e a um fortalecimento de ações participativas que possam controlar, monitora e alertar a população no geral. Os autores defendem que a governança das águas se deve basear em princípios de gestão compartilhada, descentralizada e de ampla participação pública dos usuários.

Através do computo do BHS e suas analises utilizando-se dos períodos decadais apresentado na Tabela 3 para o município de São Bento do Una - PE observam-se suas flutuações nos elementos meteorológicos que compõem o BHS. As temperaturas registradas foram elevadas nas quatros últimas décadas estudadas, os índices pluviais registaram altas irregularidades inter decadais, A ETP sofreu aumentos nas décadas 80, 90, 2000 ao passo que a EVR apresentaram os maiores poderes evaporativos nas décadas 60 e 2000, as deficiências hídricas foram reduzidas nas décadas de 60 e 2000 os excedentes hídricos seguiram as irregularidades pluviais destacando-se as décadas 70 e 2000 como de maiores excedentes hídricos.

Tabela 3. Médias decadais dos parâmetros estudados para o município de São Bento do UnaPE.

\begin{tabular}{ccccccc}
\hline Parâmetros/Décadas & $\begin{array}{c}\text { Temperatura } \\
\text { Média }(\mathrm{mm})\end{array}$ & $\begin{array}{c}\text { Chuva } \\
(\mathrm{mm})\end{array}$ & $\begin{array}{c}\text { ETP } \\
(\mathrm{mm})\end{array}$ & $\begin{array}{c}\text { EVR } \\
(\mathrm{mm})\end{array}$ & $\begin{array}{c}\text { DEF } \\
(\mathrm{mm})\end{array}$ & $\begin{array}{c}\text { EXC } \\
(\mathrm{mm})\end{array}$ \\
\hline $1950-1959$ & 21,8 & 38,6 & 88,5 & 38,9 & 49,5 & 0,5 \\
$1960-1969$ & 21,9 & 58,1 & 89,7 & 53,3 & 36,5 & 4,9 \\
$1970-1979$ & 21,8 & 54,0 & 88,9 & 48,4 & 40,5 & 5,6 \\
$1980-1989$ & 22,2 & 53,2 & 91,9 & 49,4 & 42,5 & 3,8 \\
$1990-1999$ & 22,2 & 46,1 & 93,2 & 44,0 & 49,2 & 2,2 \\
$2000-2009$ & 22,1 & 59,1 & 91,6 & 54,0 & 37,6 & 5,1 \\
$2010-2018$ & 22,0 & 44,6 & 89,6 & 41,5 & 48,1 & 3,1 \\
\hline
\end{tabular}

LEGENDA: ETP=Evapotrnaspiração; EVR=Evaporação; DEF=Deficiência hídrica; EXC=Excedente hídrico. Fonte: Medeiros, (2020). 


\section{CONCLUSÕES}

O computo do BHS demonstra as variações sazonais (temperatura, precipitação, evapotranspiração, evaporação, deficiências e excedentes hídricos), comprovam de maneira intensa as oscilações das condições hídricas da região estudada.

As análises do balanço hídrico sequencial demonstraram que os índices pluviais não foram suficientes para ocasionar excesso hídrico na região excetos par anos isolados e mesmo assim não contribuíram para armazenamento e represamento d'água, visto que os índices pluviais registrados foram abaixo da média histórica.

As variabilidades evaporimétrica e evapotranspirativas não seguiram um padrão normal entre anos, pois a influência de fenômenos sinóticos transientes atmosféricos atuantes em cada período foi detectada e mostrou-se importante alterando a evaporação e a evapotranspiração na área em estudo, e não só isto, quando chove, não havendo escoamento superficial adequado e ao término da precipitação os índices evaporativos ocorreram em maiores escalas devido à troca de calor.

Os impactos climáticos vêm ocasionando modificações no balanço hídrico regional e local das últimss quatros décadas, uma vez que a irregularidade pluvial vem acontecendo com fortes intensidades e curta duração de tempo acarretando redução nas produções avícola, agropecuária, represamento e armazenamento d'água para sobrevivência.

Destaca-se que a variabilidade espaço temporal pluvial confirmada no estudo vem influenciando, os aspectos socioambientais e socioeconômicos regionais e locais, provocados pela ação do homem o qual vem acelerado o processo de modificação do clima regional, com isso afetando diretamente as condições do regime pluvial e da disponibilidade d'água no solo.

As flutuações das deficiências hídricas no período de 1990 a 2018 foram mais acentuadas devido à irregularidade pluvial principalmente entre os meses de junho a janeiro. As irregularidades registradas nos excedente hídrico foram ocasionadas pelas chuvas e a CAD que não supriram as necessidades do solo.

Períodos de veranico prolongados, chuvas atípicas e as atuações dos fenômenos de larga escala e escala local não contribuíram para um desenvolvimento de períodos normais de chuvas.

Sugere-se que estudos devam ser realizados com balanço hídrico decendial, visando monitorar a disponibilidade hídrica da região, dando apoio aos tomadores de decisões governamentais para um melhor planejamento avícola e agropecuário. 


\section{REFERÊNCIAS}

ALMEIDA, H. A.; PEREIRA, F. C. Captação de água de chuva: uma alternativa para escassez de água. In: Congresso Brasileiro de Agrometeorologia, 15, Aracaju, SE, Anais..., Aracaju: CDROM. 2007.

ALMEIDA, H. A.; SILVA, L. Modelo de distribuição de chuvas para a cidade de Areia, PB. In: I Congresso Intercontinental de Geociências, Fortaleza, CE, Anais..., Fortaleza: CDROM. 2004.

AlvareS, C. A.; STAPE, J. L.; SENTElHAS, P. C.; GONÇALVES, J. L. M.; SPAROVEK, G. Köppen's climate classification map for Brazil. Meteorologische Zeitschrift v.22, p.711-728. 2014.

APAC. Agencia Pernambucana de água e clima. 2019.

BARBIERI, J. C. Gestão ambiental empresarial. São Paulo: Saraiva. 2007.

CAMARGO, A. P. Balanço hídrico no Estado de São Paulo. Campinas: IAC, 28p. (Boletim Técnico, 116), 1971.

CARDOSO, C. T. V. Probabilidade de Ocorrência de Deficiência Hídrica nos Solos da Região Central do Estado do Rio Grande do Sul. 2005. 186f. Tese (Doutorado em Agronomia)-Universidade Federal de Santa Maria, Santa Maria, 2005.

CAVAlCANTI, E. P.; SILVA, E. D. V. Estimativa da temperatura do ar em função das coordenadas locais. In: Congresso Brasileiro de Meteorologia, 8, Belo Horizonte, Anais...Belo Horizonte: SBMET, v.1, p.154-157. 1994.

CAVAlCANTI, E. P.; SILVA, V. P. R.; SOUSA, F. A. S. Programa computacional para a estimativa da temperatura do ar para a região Nordeste do Brasil. Revista Brasileira de Engenharia Agrícola e Ambiental. V.10, p.140-147. 2006.

COUTINHO, M. D. L; MORAIS, M. D. C. Balanço Hídrico da Climatologia Média e de Cenários Climáticos em São José de Mipibu - RN. Revista Brasileira de Geografia Física 03 p.694-707. Disponível em: <http://www.revista.ufpe.br/rbgfe/index.php/ revista/article/view/422/311>. Acesso em: 2019. 2012.

CUNHA, G. R.; ASSAD, E. D. Uma visão geral do número especial da RBA sobre zoneamento agrícola no Brasil. Revista Brasileira de Agrometeorologia, Passo Fundo, v. 9, n. 3, p. 377-385, 2001. 
FRANÇA, M. V.; FERRAZ, J. X. V.; MEDEIROS, R. M.; HOLANDA, R. M.; ROLIM NETO, F. C. Balanço hídrico entre 2000-2016 e seu comparativo com o ano de 2016 e sua influência do armazenamento de água no solo no município de Serra Talhada - PE. Tecnologias no contexto das vulnerabilidades ambientais. 1 ed. : Editora Itacaiúnas, v.1, p. 357-365. 2019,

FREITAS, J. C.; DANTAS, R. T.; ANDRADE, A. R. S.; PEREIRA, E. R. R. Analysis of variability of climatic indexes for the state of the Paraíba - PB. Pesquisa Aplicada \& Agrotecnologia v.4, n.2, Print-ISSN 1983-6325 (On line) e-ISSN 1984-7548. Disponível em: $<$ http://revistas.unicentro.br/index.php/repaa/ article/view/1333>. Acesso em: 2019. 2011.

GALVANI, E. 2011. Estatística descritiva em sala de aula. In: VENTURI, L.A.B. Geografia: Práticas de campo, laboratório e sala de aula. São Paulo: Editora Sarandi.

GARCIA, A. Balanço hídrico de Ituverava (SP) sob condições de cenários climáticos futuros. Nucleus, v.7, n.1, p. 217 - 222. abr. 2010.

HOLANDA, R. M.; MEDEIROS, R. M.; SILVA, V. P. R. Recife-PE, Brasil e suas flutuabilidades da precipitação decadal. Natureza, Sociobiodiversidade e Sustentabilidade, 26 a 29 de outubro, 2016. Universidade Nacional, Sede Chorotega Nicoya, Costa Rica. P.230-245. 2016.

IPCC. Intergovernmental Panel on Climate Change. Impacts, Adaptation, and Vulnerability. Part B: Regional Aspects. Working Group II Contribution to the Fifth Assessment Report of the Intergovernmental Panel on Climate Change. Disponível: GS. 2014.

INTERGOVERNMENTAL PANEL ON CLIMATE CHANGE (2007), Climate Change 2007: The Physical Science Basis, Contribution of Working Group I to the Fourth Assessment Report of the Intergovernmental Panel on Climate Change, edited by S. Solomon et al., Cambridge Univ. Press, Cambridge, U. K. 2007.

KÖPPEN, W. Grundriss der Klimakunde: Outline of climate science. Berlin: Walter de Gruyter. P.388. 1931.

KÖPPEN, W.; GEIGER, R. KLIMATE DER ERDE. Gotha: Verlag Justus Perthes. Wallmap $150 \mathrm{~cm} \times 200 \mathrm{~cm} .1928$.

LIMA, F. B.; SANTOS, G. O. Balanço hídrico-espacial da cultura para o uso e ocupação atual da bacia hidrográfica do Ribeirão Santa Rita, Noroeste do Estado de São Paulo. 2009. 89f. Monografia. Fundação Educacional de Fernandópolis, Fernandópolis - SP, 2009. 
LUCAS, D. D. P.; HELDWEIN, A. B.; MALDANER I. C.; TRENTIN R.; HINNAH F. D.; SILVA J. R. Excedente hídrico em diferentes solos e épocas de semeadura do girassol no Rio Grande do Sul. Pesq. agropec. bras., Brasília, v.50, n.6, p.431-440, DOI: 10.1590/S0100204X2015000600001. Disponível em: <http://www.scielo.br/pdf/pab/ v50n6/0100-204X-pab50-06-00431.pdf>. Acesso 2019. 2015.

MARENGO, J. A.; SCHAEFFER, R.; ZEE, D.; PINTO, H. S. Mudanças climáticas e eventos extremos no Brasil. Disponível em: http://www.fbds.org.br/cop15/FBDS_Mudancas Climaticas.pdf. Acessado 2019. 2015.

MARENGO, J.; SILVA, D. P. Mudanças climáticas globais e seus impactos nos recursos hídricos. Capitulo 3 em Águas Doces do Brasil: Capital Ecológico, Uso e Conservação, p.63109, Eds. A. Rebouças, B., Braga e J. Tundisi. Editoras Escrituras, SP. 2012,

MARENGO, J. A. et al. Variabilidade e mudanças climáticas no semiárido brasileiro In: Variabilidade e mudanças climáticas no semiárido brasileiro. 1 ed. Campina Grande. Instituto Nacional do Semiárido, v.1, p. 383-416, 2011.

MARENGO, J. A.; RUSTICUCCI, M.; PENALBA, O.; RENOM, M. An intercomparison of observed and simulated extreme rainfall and temperature events during the last half of the twentieth century: part 2: historical trends. Climatic Change, v. 98, n. 3-4, p. 509-529. 2010. MARENGO, J.; SILVA, D. P. Mudanças climáticas globais e seus impactos nos recursos hídricos. Capitulo 3 em Águas Doces do Brasil: Capital Ecológico, Uso e Conservação, p.63109, Eds. A. Rebouças, B., Braga e J. Tundisi. Editoras Escrituras, SP. 2008.

MARENGO, J. A.; CAMARGO, C. G. Trends in Extreme air temperatures in Southern Brazil, International Journal Climatology, v.28, p. 893-904, 2007.

MEDEIROS, R. M. Adaptação da planilha desenvolvida por ROLIM et al. no ambiente EXCEL para o cálculos de balanço hídricos sequencial. 2019.

MEDEIROS, R. M.; HOLANDA, R. M. Classificação climática e balanço hídrico pelo método de Köppen e Thornthwaite do município de Barbalha, Ceará, Brasil. Revista Equador. , v.8, p.19 - 43, 2019.

MEDEIROS, R. M.; HOLANDA, R. M.; VIANA, M. A.; SILVA, V. P. Climate classification in Köppen model for the state of Pernambuco - Brazil. Revista de Geografia (Recife). v.35, p.219-234, 2018.

MEDEIROS, R. M; KOZMHINSKY, M.; HOLANDA, R. M.; SILVA, V. P. Temperatura média do ar e suas flutuações no Estado de Pernambuco, Brasil. Revista Brasileira de Meio 
Ambiente., v.1, p.081 - 091, 2018.

MEDEIROS, R. M. Estudo Climático do Município de Matinhas-PB. Editora da Universidade Federal de Campina Grande - EDUFCG. Universidade Federal de Campina Grande-UFCG. editora@ufcg.edu.br. P.150. 2016.

MEDEIROS, R. M. Estudos dos fatores provocadores de chuvas no estado de Pernambuco - Brasil. 2016.

MEDEIROS, R. M. Formulação do balanço hídrico em planilhas eletrônicas conforme base de THORNTHWAITE, C. W. 2016.

MEDEIROS, R. M. Caracterização de mudanças climáticas por meio de séries meteorológicas para o município de Teresina/Piauí. Revista Pernambucana de Tecnologia. , v.2, p.6 - 17, 2014.

MEDEIROS, R. M.; AZEVEDO, P. V.; SABOYA, L. M. F.; Classificação climática e zoneamento agroclimático para o município de Amarante - PI. Revista Brasileira de Agricultura Irrigada, v. 7, n. 2, p. 170 - 180, 2013.

MEDEIROS, R. M.; BANDEIRA, M. M. Balanço Hídrico Climatológico, em Decorrência do Aquecimento Global, no Município de Picuí - Semiárido Paraibano. Revista Brasileira de Geografia Física. V.01, p. 59-72. 2012.

MEDEIROS, R. M.; TAVARES, A. L.; KASSAR, C. B.; SILVA, J. A. S.; SILVA, V. P. R. Metodologias de cálculo da temperatura média diária do ar: aplicação para os municípios de Parnaíba, Picos e Gilbués, PI. Revista Brasileira de Agricultura Irrigada. v.6, nº. 4, p. 283 $-295.2012$.

NEVES, S. M. A. S.; NUNES, M. C. M.; NEVES, R. J. Caracterização das condições climáticas de Cáceres/MT - Brasil, no período de 1971 a 2009: subsídio às atividades agropecuárias e turísticas municipais. B.goiano.geogr, Goiânia, v.31, n.2, p.55-68, Disponível em: <https://revistas.ufg.emnuvens. com.br/bgg/article/view/16845/10255>. Acesso 2019. 2011.

NOBRE, C. A.; ASSAD, E. D. Aquecimento Global e o Impacto na Amazônia e na Agricultura Brasileira. INPE Eprint. V.1, 2005. Disponível em: <http://www.sid.inpe.br/ePrint@80/2005/09.12.12.51>. Acesso em: nov. 2019.

A Organização Meteorológica Mundial (WMM,) propõem que em estudos comparativos de clima, utilizem-se das séries médias históricas para períodos com mais de 30 anos de observações para as séries em estudos, para tanto os dados precisam ter consistência e 
homogeneidade na sua comparação dos seus valores analisados. 1989.

OMETTO, J. C. Bioclimatologia vegetal. São Paulo: Ceres, 440p. 1981.

PEREIRA, A. R.; ANGELOCCI, L. R.; SENTELHAS, P. C. Agrometeorologia: fundamentos e aplicações práticas. Agropecuária, 478p. 2002.

ORLANDINI, D. et al. Potencialidades das regiões brasileiras para instalação de uma fábrica de celulose. Revista Árvore, Viçosa-MG, v.35, n.5, p.1053-1060, 2011.

PEDDE, S. C.; KROEZE, R. L. N. Escassez hídrica na América do sul: situação atual e perspectivas futuras. XX Simpósio Brasileiro de Recursos Hídricos. 2013.

ROLIM, G. S.; SENTELHAS, P. C.; BARBIERI, V. Planilhas no ambiente EXCEL para os cálculos de balanços hídricos: normal, sequencial de cultura e de produtividade real e potencial. Revista Brasileira de Agrometeorologia, Santa Maria, v. 6,n.1,p133-137,1998.

SACHS, J. D. The age of sustainable development. New York, US: Columbia University Press. 2015.

SALES, M. C. L. Estudo da degradação ambiental em Gilbués-PI. Reavaliando o "núcleo de desertificação”. Dissertação (Mestrado em Geografia) USP/FFLCH, São Paulo. 1998.

SANTOS, G. O.; LIMA, F. B.; VANZELA, L. S. Balanço hídrico espacial das culturas inseridas na bacia hidrográfica do Ribeirão Santa Rita, noroeste paulista. Revista Brasileira de Agricultura Irrigada. v.7, $\mathrm{n}^{\circ}$. 1, p. 03-16, ISSN 1982-7679 (On-line). Fortaleza, CE, INOVAGRI. DOI: 10.7127/rbai.v7n100091. 2013.

SILVA, M. C. L.; BRITO, J. I. B.; COSTA, A. M. N. Proposta de monitoramento da precipitação pluvial no estado da Paraíba utilizando a técnica dos Quantis. In: Congresso Brasileiro de Meteorologia, XIII, Fortaleza-CE. Anais...SBMET. 2006.

SHUTTLEWORTH, W. J. Evaporation. IN MAIDMENT, D. R. (Ed.) Handbook of Hydrology. New York, McGraw-Hill Inc. 1993.

SINGH, V. P.; XU, C. Y. Evaluation and Generalization of 13 Equations for Determining Free Water Evaporation, Hydrol. Processes11, p.311-323, 1997.

SUDENE. Normais Climatológicas da Área da SUDENE. Superintendência do Desenvolvimento do Nordeste. Convênio com o Serviço de Meteorologia, Recife. 1990.

SOUZA, A. P.; et al. Classificação climática e balanço hídrico climatológico no Estado de Mato Grosso. Nativa, Sinop, v. 01, n. 01, p. 34 - 43, 2015. 
SOUSA, E. S.; LIMA, F. W. B.; MACIEL, G. F.; SOUSA, J. P.; PICANÇO, A. P. 2010. Balanço hídrico e classificação climática de Thornthwaite para a cidade de Palmas-TO. XVI Congresso Brasileiro de Meteorologia, Belém-PA, Anais on line, 2010.

SOUZA, M. J. H. et al. Disponibilidade hídrica do solo e produtividade do eucalipto em três regiões da bacia do Rio Doce. R. Árvore, 30[3], 399-410, 2006.

THORNTHWAITE, C. W. An approach toward a rational classification of climate. Geogr. Rev, v.38, p.55-94, 1948.

THORNTHWAITE, C. W.; MATHER, J. R. The water balance. Publications in Climatology. New Jersey: Drexel Institute of Technology, 104p. 1955.

XU, C. Y.; SINGH, V. P. Evaluation and Generalization of Radiation-based Methods for Calculating Evaporation, Hydrolog. Processes 14, p.339-349, 2000.

XU, C. Y. SINGH, V. P. Evaluation and Generalization of Radiation-based Methods for Calculating Evaporation, Hydrolog. Processes 15, p.305-319, 2001. 